\title{
Synthesis, Reactions and Antimicrobial Activity of 2-Amino-4-(8-quinolinol-5-yl)-1-(p-tolyl)-pyrrole-3-carbonitrile
}

\author{
Shawkat A. Abdel-Mohsen \\ Chemistry Department, Faculty of Science, Assiut University, Assiut 71516, Egypt \\ *E-mail: shawk662001@yahoo.com \\ Received December 28, 2004
}

\begin{abstract}
A novel 2-amino-4-(8-quinolinol-5-yl)-1- ( $p$-tolyl)-pyrrole-3-cabonitrile (2) was obtained by the reaction of 2[2-bromo-1-(8-hydroxyquinolin-5-yl)-ethylidene]-malononitrile (1) with $p$-toluidene. The new synthon compound (2) could be annelated to the corresponding pyrrolo[2,3- $d]$ pyrimidines $(\mathbf{4}, \mathbf{6}, \mathbf{7}, \mathbf{2 6 - 2 8})$, triazolo[1,5c]pyrrolo[3,2-e]pyrimidines $(\mathbf{1 0}, \mathbf{2 9}, \mathbf{3 0})$, pyrrolo[2,3-c]pyrazoles (11-15), pyrrolo[1,2- $a]$ pyrrolo[3,2-e] pyrimidine (17) and imidazo[1,2-c]pyrrolo[3,2-e]pyrimidines (18-25) via the reaction with some reagents such as acetic anhydride, formamide, triethyl orthoformate, hydrazine hydrate, hydroxylamine, ethylenediamine, carbon disulfide and phosphorus oxychloride. Chemical and spectroscopic evidences for the structures of these compounds are presented. The antifungal and antibacterial activity of the newly synthesized comounds were evaluated.
\end{abstract}

Key Words : 5-Pyrrolo-8-quinolinol, Pyrrolopyrimidines, Triazoles, Imidazoles, Antimicrobial activity

\section{Introduction}

Various pyrrolo[2,3- $d$ ]pyrimidines have been substantially investigated as a part of the synthesis of new C-nucleosides with potential biomedical interest, since they have been found to exhibit pronounced growth inhibitory activity to several leukemic cell lines. ${ }^{1-4}$ Also, it was reported that these compounds possess analgesic, anti-inflammatory, CNS depressant, anticonvulsant and sedative activities. ${ }^{5-9}$ With all the above facts in mind and as a part of our program directed towards the synthesis of poly functionally substituted 5heterocyclo-8-quinolinoles of potential biological interest, ${ }^{10-14}$ we aimed to report herein the preparation of a new 2-amino4-(8-quinolinol-5-yl)-1-(p-tolyl)-pyrrole-3-cabonitrile (2) as a conveniently accessible precursor for the synthesis of pyrrolo[2,3- $d]$ pyrimidines and other related heterocyclic systems.

\section{Results and Discussion}

Our approach to the target heterocyclic compounds was achieved by the synthesis of 2-amino-4-(8-quinolinol-5-yl)1-( $p$-tolyl)-pyrrole-3-cabonitrile (2) which was prepared by heating an equimolar amounts of 2-[2-bromo-1-(8quinolinol-5-yl)-ethylidene]-malononitrile (1) and $p$-toluidine under mild Gewald reaction condition. ${ }^{15}$ The above-mentioned pyrroles which contain the $\beta$-enaminonitrile moiety are well known to be highly reactive and were used as intermediates for the synthesis of new pyrrolo[2,3- $d]$ pyrimidine derivatives. Thus, condensation of $\mathbf{2}$ with triethyl orthoformate in refluxing acetic anhydride afforded the intermediate ethoxymethyleneamino derivative $\mathbf{3}$, which was isolated and used without purification in the next step. Thus, Stirring of 3 with hydrazine hydrate in dry benzene at room temperature for $7 \mathrm{~h}$, gave 5-amino-4-iminopyrrolo[2,3- $d]$ pyrimidine derivative 4 . On the other hand, when 2 was boiled in acetic anhydride, the reaction product was the diacetyl derivative $\mathbf{5}$, while its heating in acetic anhydride- pyridine mixture gave 5-(8-quinolinol-5-yl)-2-methyl-7-( $p$-tolyl)-pyrrolo[2,3-d] pyrimidine-4(3H)-one (6). Also, treatment of $\mathbf{2}$ with formamide yielded 4-aminopyrrolo[2,3- $d]$ pyrimidine (7).

Earlier work has discribed the direct conversion of the cyano function of $o$-amino nitrile into the corresponding 4,5dihydro- $1 H$-imidazol-2-yl group via the reaction of the amino nitrile with ethylenediamine in the presence of carbon disulfide or phosphorus pentasulfide. ${ }^{16,17}$ Accordingly, 2amino-4-(8-quinolinol-5-yl)-1-( $p$-tolyl)-3-(4,5-dihydro- $1 H$ imidazol-2-yl)-pyrrole (8) could be obtained via the refluxing of 2 with ethylenediamine in the presence of carbon disulfide. Compound 2, in turn, was allowed to react with an equimolar amounts of chloroacetyl chloride in dry dioxane solution under reflux afforded the corresponding 2( $\alpha$-chloroacetamido) derivative 9 (Scheme 1).

Cyclocondensation of $\mathbf{4}$ with triethyl orthoformate and/or acetyl chloride resulted in the formation of triazolo[1,5-c] pyrrolo[3,2-e]pyrimidine derivatives $\mathbf{1 0 a}$ and $\mathbf{1 0 b}$ respectively, while reaction of $\mathbf{4}$ with chloroacetyl chloride and/or ethyl cyano-acetate afforded the corresponding triazolo 2chloromethyl and 2-cyanomethyl derivatives 10c and 10d, respectively (Scheme 2). The mass fragmentation pattern of the triazolopyrrolopyrimidine derivative 10a was also in agreement with that reported for fused triazolopyrimidines, ${ }^{18}$ 
<smiles>Nc1ncnc2c1c(-c1ccc(O)c3ncccc13)cn2[Al]</smiles>

7<smiles>N#CC(C#N)=C(CBr)c1ccc(O)c2ncccc12</smiles>

1<smiles></smiles>

8 $\mathrm{NH}_{2}\left(\mathrm{CH}_{2}\right)_{2} \mathrm{NH}_{2} / \mathrm{CS}_{2}$

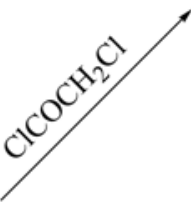

$\mathrm{CH}(\mathrm{OEt})_{3}$ $\underset{n \text {-Propanol }}{\stackrel{p \text {-toluidine }}{\longrightarrow}}$

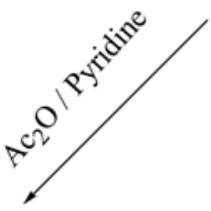<smiles></smiles>

6<smiles>N#Cc1c(-c2ccc(O)c3ncccc23)cn(Cl)c1N</smiles>

2

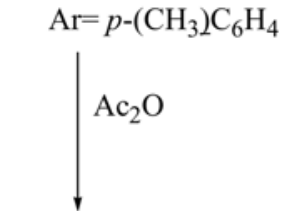<smiles>CC(=O)Nc1c(C#N)c(O)c2ncccc2c1-c1ccn(Cl)c1</smiles>

Scheme 1<smiles></smiles><smiles>CCO/C=N/c1cn([Al])cc1-c1ccc(O)c2ncccc12</smiles>

$\mathrm{N}_{2} \mathrm{H}_{4} \cdot \mathrm{H}_{2} \mathrm{O}$<smiles>CN(C=C(c1cccnc1)c1ccc(O)c2ncccc12)C(=N)N</smiles>

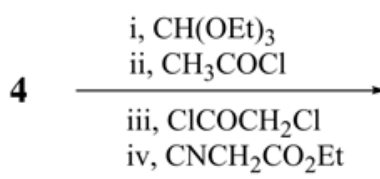<smiles>[R]c1nc2c(C(=CN(C)[Al])c3ccc(O)c4ncccc34)c(C)ncn2n1</smiles>

a: $\mathrm{R}=\mathrm{H}$

b: $\mathrm{R}=\mathrm{CH}_{3}$

c: $\mathrm{R}=\mathrm{CH}_{2} \mathrm{Cl}$

d: $\mathrm{R}=\mathrm{CH}_{2} \mathrm{CN}$

Scheme 2

showing $\mathrm{M}^{+}$peak at 392 together with signals at $\mathrm{m} / \mathrm{z} 365$, 364 and 337 resulting from subsequent removal of nitrogen
$\left(\mathrm{N}_{2}\right)$ and hydrogen cyanide $(\mathrm{HCN})$ or hydrogen cyanide and nitrogen molecules (Scheme 3).

On the other hand, compound 2 reacted with an equimolar amount of hydroxylamine hydrochloride in glacial acetic acid in the presence of anhydrous sodium acetate under reflux to provide 3-amino-4-(8-quinolinol-5-yl)-1H-Pyrrolo $[2,3-c]$ pyrazole (11), which is used as a starting compound for other heterocyclic systems. Thus, condensation of $\mathbf{1 1}$ with benzaldehyde afforded the schiff's base 12. On treatment of $\mathbf{1 1}$ with acetyl acetone and/ or ethyl acetoacetate a ring closure occurred and the corresponding pyrimidopyrrolopyrazolo derivatives 13 and 14 were obtained. The reaction of $\mathbf{1 1}$ with phenyl isothiocyanate by heating in pyridine gave the thiourea derivative $\mathbf{1 5}$ (Scheme 4 ).

On treatment of compound 9 with malononitrile in dioxane solution containing a catalytic amount of triethyl amine as $\mathrm{HCl}$ acceptor, gave the pyrrolo[1,2-a]pyrrolo[3,2- 
<smiles></smiles>

$m / z=392$ $-\mathrm{N}_{2}(28)$<smiles></smiles>

$m / z=364$

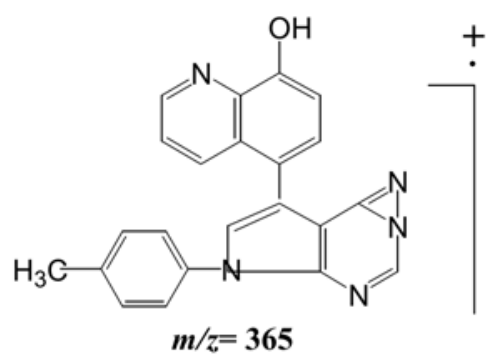

$-\mathrm{N}_{2}(28)$

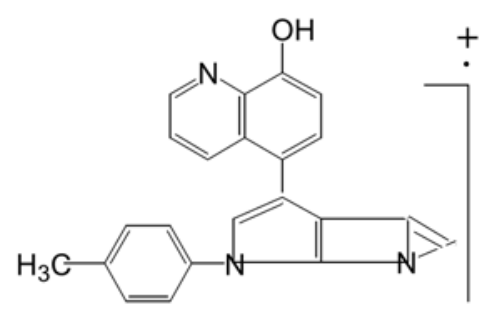

$m / z=337$

Scheme 3. Mass Fragmentation Pattern of Compound 10a

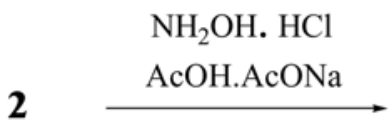

$\mathrm{NH}_{2} \mathrm{OH} . \mathrm{HCl}$

- HCN (27)<smiles>Nc1n[nH]c2c1c(-c1ccc(O)c3ncccc13)cn2C1CCCCC1</smiles>

11<smiles>Oc1ccc(-c2cn([Al])c3[nH]nc(NC(=S)Nc4ccccc4)c23)c2cccnc12</smiles>

15

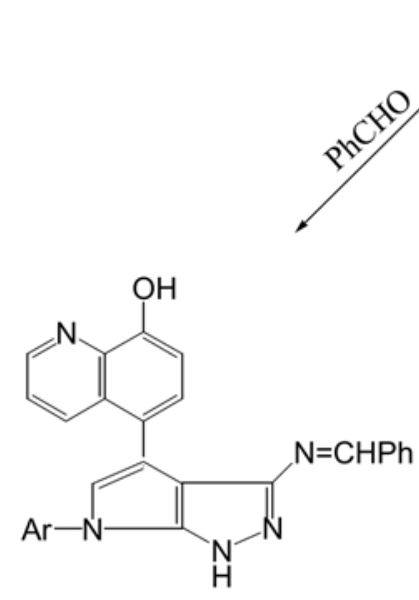

12
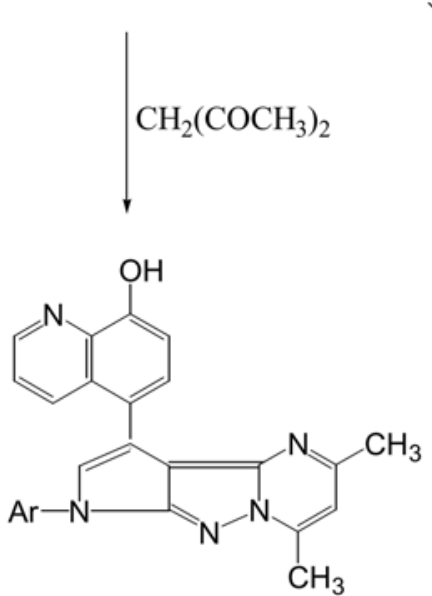

13

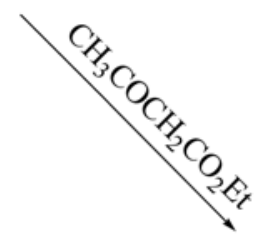<smiles>Cc1cc(=O)n2nc3c(c(-c4ccc(O)c5ncccc45)cn3[Al])c2[nH]1</smiles>

14

Scheme 4

e]pyrimidine-6-cabonitrile derivative $\mathbf{1 7}$. Formation of $\mathbf{1 7}$ is assumed to proceed via intermediate $\mathbf{1 6}$ followed by subsequent intramolecular cyclization via a Micheal type nucleophilic addition of the $\mathrm{NH}_{2}$ to the neighbouring $\mathrm{C}-3$ $\mathrm{CN}$ function (Scheme 5).
The imidazolinyl derivative $\mathbf{8}$ is a versatile compound and could serve as a point of departure for the synthesis of some fused tricyclic heterocycles. Thus, condensation of $\mathbf{8}$ with triethyl orthoformate in the presence of a few drops of acetic acid furnished the pyrazolopyrimidine derivative (18). Also, 
9

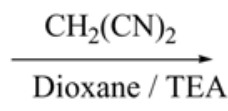

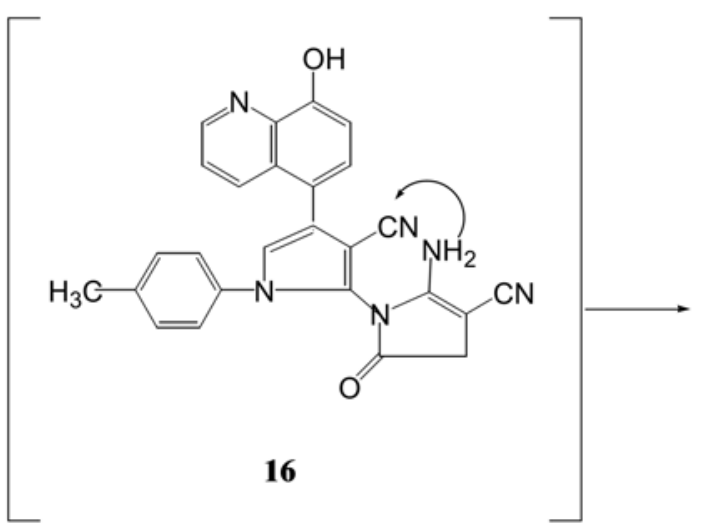

Scheme 5<smiles></smiles>

17

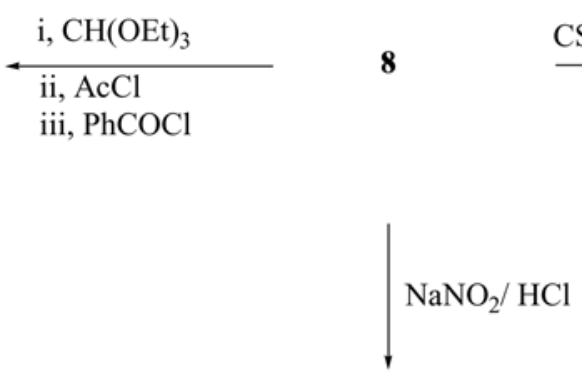<smiles>CCn1cc(-c2ccc(O)c3ncccc23)c2c1N=NN1CCN=C21</smiles>

25

\section{$\mathrm{CS}_{2} /$ Pyridine}

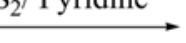<smiles>Oc1ccc(-c2cn(Cl)c3c2C2=NCCN2C(=S)N3)c2cccnc12</smiles>

$\mathrm{R}-\mathrm{X}$<smiles></smiles>

22, $\mathrm{R}=\mathrm{C}_{2} \mathrm{H}_{5}$

23, $\mathrm{R}=\mathrm{CH}_{2} \mathrm{CO}_{2} \mathrm{Et}$

24, $\mathrm{R}=\mathrm{CH}_{2} \mathrm{COPh}$

Scheme 6

treatment of compound $\mathbf{8}$ with acetyl and/or benzoyl chloride afforded the corresponding 2-methyl and 2phenylpyrimidine derivatives 19 and 20, respectively. The reaction of $\mathbf{8}$ with carbon disulfide in pyridine yielded the imidazopyrimidine thione derivative (21), which was easily S-alkylated with ethyl iodide, a-chloroethylacetate and/ or phenacyl bromide to give the substituted mercapto derivatives 22-24, respectively. Diazotization of 8 with sodium nitrite in acetic acid- $\mathrm{HCl}$ mixture afforded the triazine derivative (25) (Scheme 6).

On the other hand, chlorination of the pyrrolopyrimidinone derivative (6) with $\mathrm{POCl}_{3}$ afforded the chloro compound 26. Hydrazinolysis of the chloro compound 26 with hydrazine hydrate in refluxing ethanol gave 4-hydrazino-2-methylpyrrolo [2,3- $d]$ pyrimidine derivative (27). The structure of the hydrazino compound 27 was established chemically using several chemical reactions, and it was served as a starting material for other interesting tricycles. Thus, The azide derivative $\mathbf{2 8}$ was obtained through its reaction with sodium nitrite in acetic acid. Other new derivatives of triazolo compounds $\mathbf{2 9}$ and $\mathbf{3 0}$ were synthesized from the hydrazino compound via the reaction with carbon disulfide in pyridine or ethyl chloroformate, respectively (Scheme 7).

\section{Biological Activity}

Most of the synthesized compounds were screened in vitro for their antimicrobial activities against two strains of bacteria (Bacillus cereus, Escherichia coli) and two strains of fungi (Aspergillus flavus, Stachybortys atra) using the filter paper disc method. ${ }^{19}$ The relationship between the 
<smiles></smiles>

26
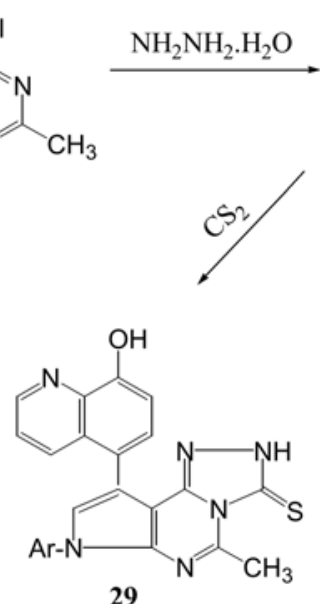
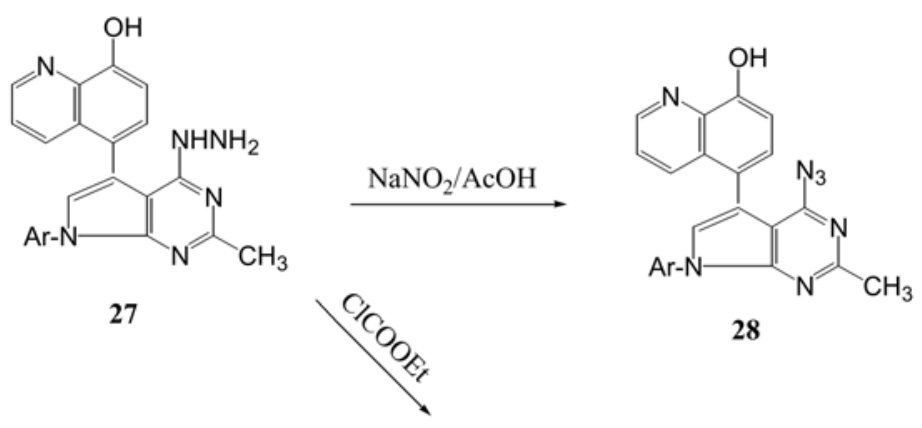

28

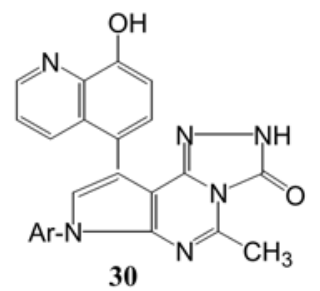

Scheme 7

structure and the antibacterial activity is quite clear for the results depicted in Table 1. The following generalizations in this aspect may be made:

Antibacterial activity. The $\mathrm{N}$-( $p$-tolyl)pyrrolo derivative 2 have a considerable activity against the tested bacteria. Conversion of the amino group by an ethoxymethyleneamino one (3) found to be more active. Among the pyrrolopyrimidines compounds $(4,6,26,27)$, only 4-chloro2-methyl one (26) exhibited promising activity towards both the investigated bacteria species. Building up another fused traizolopyrimidine ring systems (10a-d) exhibited a variable activity depending on the type of substituents at C-2 in the traizole ring, thus 2-cyanomethyl isomer (10d) possessed the highest antimicrobial activity. Also the thiotriazolo derivative (29) is more active than its oxotriazolo one (30) especially with $B$. cereus. From the comparison of pyrrolopyrazolo compounds, only the parent one (11) and its thiourea derivative (15) gave the highest activity against $E$. coli. Among the imidazopyrimidine derivatives 18-20, only the phenyl substituent one $\mathbf{2 0}(\mathrm{R}=\mathrm{ph})$ exhibited a promising antibacterial activity against the bacteria organisms. The imidazothiopyrimidine and its S-alkylated derivatives (2124) possessed a moderate activity against the tested bacteria species (Table 1).

Antifungal activity. The results from Table 1 revealed that some of the synthesized compounds 2-30 gave positive results against the fungi species. Thus, only 2-diacetylamino; 2-chloro-methyltriazolopyrimidine; 3-aminopyrazolo; 2-benzoylmetyhlthioimidazo triazine; 4-chloromethylpyrimidine derivatives $\mathbf{5}, \mathbf{1 0 c}, \mathbf{1 1}, \mathbf{2 4}, \mathbf{2 6}$, respectively revealed strongest activity against $A$. flavus. Other compounds possessed mild to moderate activity against the investigated fungi species.

\section{Experimental Section}

Melting points were uncorrected and determined using a
Table 1. Antibacterial and antifungal activities for most of synthesized compounds (diameter of inhibition zones, $\mathrm{mm}$ )

\begin{tabular}{ccccc}
\hline Compd no & B. cereus & E. coli & A. flavus & S. atra \\
\hline $\mathbf{2}$ & 13 & 18 & $-\mathrm{ve}$ & 11 \\
$\mathbf{3}$ & 22 & 27 & 9 & 11 \\
$\mathbf{4}$ & 8 & $-\mathrm{ve}$ & 5 & $-\mathrm{ve}$ \\
$\mathbf{5}$ & 12 & 14 & 17 & $-\mathrm{ve}$ \\
$\mathbf{6}$ & 20 & 24 & $-\mathrm{ve}$ & $-\mathrm{ve}$ \\
$\mathbf{1 0 a}$ & 32 & 11 & 9 & $-\mathrm{ve}$ \\
$\mathbf{1 0 b}$ & $-\mathrm{ve}$ & 13 & $-\mathrm{ve}$ & $-\mathrm{ve}$ \\
$\mathbf{1 0 c}$ & $-\mathrm{ve}$ & $-\mathrm{ve}$ & 20 & 4 \\
$\mathbf{1 0 d}$ & 25 & 41 & $-\mathrm{ve}$ & 16 \\
$\mathbf{1 1}$ & 20 & 33 & 34 & $-\mathrm{ve}$ \\
$\mathbf{1 3}$ & $-\mathrm{ve}$ & $-\mathrm{ve}$ & $-\mathrm{ve}$ & $-\mathrm{ve}$ \\
$\mathbf{1 5}$ & 19 & 41 & 7 & 7 \\
$\mathbf{1 7}$ & 7 & 9 & 11 & 6 \\
$\mathbf{1 8}$ & $-\mathrm{ve}$ & $-\mathrm{ve}$ & $-\mathrm{ve}$ & $-\mathrm{ve}$ \\
$\mathbf{1 9}$ & $-\mathrm{ve}$ & $-\mathrm{ve}$ & 15 & 19 \\
$\mathbf{2 0}$ & 44 & 37 & $-\mathrm{ve}$ & 6 \\
$\mathbf{2 2}$ & 19 & 23 & 8 & 9 \\
$\mathbf{2 3}$ & 16 & 12 & $-\mathrm{ve}$ & 7 \\
$\mathbf{2 4}$ & 22 & 10 & 33 & 5 \\
$\mathbf{2 5}$ & 12 & 16 & 4 & 7 \\
$\mathbf{2 6}$ & 36 & 33 & 41 & 16 \\
$\mathbf{2 7}$ & $-\mathrm{ve}$ & $-\mathrm{ve}$ & $-\mathrm{ve}$ & $-\mathrm{ve}$ \\
$\mathbf{2 9}$ & 36 & 22 & 7 & 9 \\
$\mathbf{3 0}$ & 6 & $-\mathrm{ve}$ & $-\mathrm{ve}$ & $-\mathrm{ve}$ \\
Tioconazole & 11 & $-\mathrm{ve}$ & 21 & 12 \\
Tyrosyd $^{\mathbf{R}}$ ) & & & & \\
\hline$-\boldsymbol{- v e}$ & & & & \\
\hline & & & & \\
\hline
\end{tabular}

*-ve:. No Inhibition zone

Kofler melting point apparatus. IR spectra were recorded on a Pye Unicam SP3-100 spectrophotometer using KBR wafer technique. ${ }^{1} \mathrm{H}$ NMR spectra were recorded on a Varian EM$39090 \mathrm{MHZ}$ spectrometer in a suitable deutrated solvent using TMS as internal standard. Mass spectra were measured on a Jeol JMS-600 spectrometer. Elemental analyses were determined on a Perkin-Elmer $240 \mathrm{C}$ 
Table 2. Analytical data of the newly synthesized compounds

\begin{tabular}{|c|c|c|c|c|c|c|c|}
\hline \multirow{2}{*}{ No } & \multirow{2}{*}{$\begin{array}{l}\text { Formula } \\
\text { (M.Wt) }\end{array}$} & \multicolumn{6}{|c|}{ Calculated / Found } \\
\hline & & $\% \mathrm{C}$ & $\% \mathrm{H}$ & $\% \mathrm{~N}$ & $\% \mathrm{~S}$ & $\% \mathrm{Cl}$ & $\% \mathrm{Br}$ \\
\hline \multirow[t]{2}{*}{1} & $\mathrm{C}_{14} \mathrm{H}_{8} \mathrm{BrN}_{3} \mathrm{O}$ & 53.53 & 2.55 & 13.38 & & & 25.44 \\
\hline & (314.14) & 53.49 & 2.57 & 13.39 & & & 25.35 \\
\hline \multirow[t]{2}{*}{2} & $\mathrm{C}_{21} \mathrm{H}_{16} \mathrm{~N}_{4} \mathrm{O}$ & 74.10 & 4.74 & 16.46 & & & \\
\hline & $(340.38)$ & 73.89 & 4.71 & 16.53 & & & \\
\hline \multirow[t]{2}{*}{3} & $\mathrm{C}_{24} \mathrm{H}_{20} \mathrm{~N}_{4} \mathrm{O}_{2}$ & 72.71 & 5.08 & 14.13 & & & \\
\hline & $(398.44)$ & 72.75 & 4.93 & 14.08 & & & \\
\hline \multirow[t]{2}{*}{4} & $\mathrm{C}_{22} \mathrm{H}_{18} \mathrm{~N}_{6} \mathrm{O}$ & 69.10 & 4.74 & 21.98 & & & \\
\hline & $(382.44)$ & 68.21 & 4.70 & 21.84 & & & \\
\hline \multirow[t]{2}{*}{5} & $\mathrm{C}_{25} \mathrm{H}_{20} \mathrm{~N}_{4} \mathrm{O}_{3}$ & 70.74 & 4.75 & 13.20 & & & \\
\hline & $(424.45)$ & 70.69 & 4.73 & 13.11 & & & \\
\hline \multirow[t]{2}{*}{6} & $\mathrm{C}_{23} \mathrm{H}_{18} \mathrm{~N}_{4} \mathrm{O}_{2}$ & 72.24 & 4.74 & 14.65 & & & \\
\hline & $(382.41)$ & 72.31 & 4.79 & 14.59 & & & \\
\hline \multirow[t]{2}{*}{7} & $\mathrm{C}_{22} \mathrm{H}_{17} \mathrm{~N}_{5} \mathrm{O}$ & 71.92 & 4.66 & 19.06 & & & \\
\hline & $(367.40)$ & 71.81 & 4.66 & 19.26 & & & \\
\hline \multirow[t]{2}{*}{8} & $\mathrm{C}_{23} \mathrm{H}_{21} \mathrm{~N}_{5} \mathrm{O}$ & 72.04 & 5.52 & 18.26 & & & \\
\hline & $(383.45)$ & 71.89 & 5.46 & 18.07 & & & \\
\hline \multirow[t]{2}{*}{9} & $\mathrm{C}_{23} \mathrm{H}_{17} \mathrm{ClN}_{4} \mathrm{O}_{2}$ & 66.27 & 4.11 & 13.44 & & 8.50 & \\
\hline & $(416.86)$ & 66.41 & 4.02 & 13.21 & & 8.32 & \\
\hline \multirow[t]{2}{*}{$10 \mathbf{a}$} & $\mathrm{C}_{23} \mathrm{H}_{16} \mathrm{~N}_{6} \mathrm{O}$ & 70.40 & 4.11 & 21.42 & & & \\
\hline & $(392.41)$ & 70.29 & 4.03 & 21.28 & & & \\
\hline \multirow[t]{2}{*}{$10 \mathrm{~b}$} & $\mathrm{C}_{24} \mathrm{H}_{18} \mathrm{~N}_{6} \mathrm{O}$ & 70.92 & 4.46 & 20.68 & & & \\
\hline & $(406.44)$ & 70.82 & 4.51 & 20.62 & & & \\
\hline \multirow[t]{2}{*}{$10 \mathrm{c}$} & $\mathrm{C}_{24} \mathrm{H}_{17} \mathrm{ClN}_{6} \mathrm{O}$ & 65.38 & 3.89 & 19.06 & & 8.04 & \\
\hline & $(440.88)$ & 65.27 & 3.81 & 19.19 & & 7.89 & \\
\hline \multirow[t]{2}{*}{ 10d } & $\mathrm{C}_{25} \mathrm{H}_{17} \mathrm{~N}_{7} \mathrm{O}$ & 69.60 & 3.97 & 22.73 & & & \\
\hline & $(431.44)$ & 69.81 & 3.81 & 22.91 & & & \\
\hline \multirow[t]{2}{*}{11} & $\mathrm{C}_{21} \mathrm{H}_{17} \mathrm{~N}_{5} \mathrm{O}$ & 70.97 & 4.82 & 19.71 & & & \\
\hline & $(355.39)$ & 70.88 & 4.72 & 19.68 & & & \\
\hline 12 & $\mathrm{C}_{28} \mathrm{H}_{21} \mathrm{~N}_{5} \mathrm{O}$ & 75.83 & 4.77 & 15.79 & & & \\
\hline & $(443.50)$ & 75.71 & 4.62 & 15.59 & & & \\
\hline 13 & $\mathrm{C}_{26} \mathrm{H}_{21} \mathrm{~N}_{5} \mathrm{O}$ & 74.44 & 5.05 & 16.70 & & & \\
\hline & $(419.48)$ & 74.32 & 4.87 & 16.62 & & & \\
\hline 14 & $\mathrm{C}_{25} \mathrm{H}_{19} \mathrm{~N}_{5} \mathrm{O}_{2}$ & 71.25 & 4.54 & 16.62 & & & \\
\hline & $(421.45)$ & 71.33 & 4.55 & 16.71 & & & \\
\hline 15 & $\mathrm{C}_{28} \mathrm{H}_{22} \mathrm{~N}_{6} \mathrm{OS}$ & 68.55 & 4.52 & 17.13 & 6.54 & & \\
\hline & $(490.58)$ & 68.72 & 4.44 & 17.28 & 6.42 & & \\
\hline 17 & $\mathrm{C}_{27} \mathrm{H}_{19} \mathrm{~N}_{5} \mathrm{O}_{2}$ & 72.80 & 4.30 & 15.72 & & & \\
\hline & $(445.47)$ & 72.63 & 4.23 & 15.79 & & & \\
\hline 18 & $\mathrm{C}_{24} \mathrm{H}_{19} \mathrm{~N}_{5} \mathrm{O}$ & 73.27 & 4.87 & 17.80 & & & \\
\hline & $(393.44)$ & 73.18 & 4.81 & 17.69 & & & \\
\hline 19 & $\mathrm{C}_{25} \mathrm{H}_{21} \mathrm{~N}_{5} \mathrm{O}$ & 73.69 & 5.19 & 17.19 & & & \\
\hline & $(407.47)$ & 73.58 & 5.08 & 17.25 & & & \\
\hline 20 & $\mathrm{C}_{30} \mathrm{H}_{23} \mathrm{~N}_{5} \mathrm{O}$ & 76.74 & 4.94 & 14.92 & & & \\
\hline & $(469.54)$ & 76.59 & 4.91 & 14.78 & & & \\
\hline 21 & $\mathrm{C}_{24} \mathrm{H}_{19} \mathrm{~N}_{5} \mathrm{OS}$ & 67.74 & 4.50 & 16.46 & 7.54 & & \\
\hline & $(425.51)$ & 67.91 & 4.39 & 16.28 & 7.49 & & \\
\hline 22 & $\mathrm{C}_{26} \mathrm{H}_{23} \mathrm{~N}_{5} \mathrm{OS}$ & 68.85 & 5.11 & 15.44 & 7.07 & & \\
\hline & $(453.56)$ & 68.74 & 5.01 & 15.38 & 6.89 & & \\
\hline 23 & $\mathrm{C}_{28} \mathrm{H}_{25} \mathrm{~N}_{5} \mathrm{O}_{3} \mathrm{~S}$ & 65.74 & 4.93 & 13.69 & 6.27 & & \\
\hline & $(511.60)$ & 65.66 & 4.88 & 13.52 & 6.19 & & \\
\hline 24 & $\mathrm{C}_{32} \mathrm{H}_{25} \mathrm{~N}_{5} \mathrm{O}_{2} \mathrm{~S}$ & 70.70 & 4.64 & 12.88 & 5.90 & & \\
\hline & $(543.64)$ & 70.64 & 4.72 & 12.97 & 5.79 & & \\
\hline 25 & $\mathrm{C}_{23} \mathrm{H}_{18} \mathrm{~N}_{6} \mathrm{O}$ & 70.04 & 4.60 & 21.31 & & & \\
\hline & $(394.43)$ & 69.79 & 4.65 & 21.18 & & & \\
\hline
\end{tabular}

Table 2. Continued

\begin{tabular}{cccccccc}
\hline \multirow{2}{*}{ No } & \multirow{2}{*}{$\begin{array}{c}\text { Formula } \\
\text { (M.Wt) }\end{array}$} & \multicolumn{6}{c}{ Calculated / Found } \\
\cline { 3 - 8 } & & $\% \mathrm{C}$ & $\% \mathrm{H}$ & $\% \mathrm{~N}$ & $\% \mathrm{~S}$ & $\% \mathrm{Cl}$ & $\% \mathrm{Br}$ \\
\hline $\mathbf{2 6}$ & $\mathrm{C}_{23} \mathrm{H}_{17} \mathrm{ClN}_{4} \mathrm{O}$ & 68.91 & 4.27 & 13.98 & & & 8.84 \\
& $(400.86)$ & 68.71 & 4.22 & 13.71 & & 8.81 \\
$\mathbf{2 7}$ & $\mathrm{C}_{23} \mathrm{H}_{20} \mathrm{~N}_{6} \mathrm{O}$ & 69.68 & 5.08 & 21.20 & & & \\
& $(396.44)$ & 69.48 & 5.12 & 21.11 & & \\
$\mathbf{2 8}$ & $\mathrm{C}_{23} \mathrm{H}_{17} \mathrm{~N}_{7} \mathrm{O}$ & 67.80 & 4.21 & 24.06 & & \\
& $(407.43)$ & 67.59 & 4.08 & 24.17 & & \\
$\mathbf{2 9}$ & $\mathrm{C}_{24} \mathrm{H}_{18} \mathrm{~N}_{6} \mathrm{OS}$ & 65.74 & 4.14 & 19.17 & 7.31 & \\
& $(438.51)$ & 65.87 & 4.26 & 19.39 & 7.27 & \\
$\mathbf{3 0}$ & $\mathrm{C}_{24} \mathrm{H}_{18} \mathrm{~N}_{6} \mathrm{O}_{2}$ & 68.24 & 4.29 & 19.89 & & \\
& $(422.44)$ & 68.22 & 4.23 & 19.80 & & \\
\hline
\end{tabular}

microanalyzer and the results were listed in Table 2. 5Acetyl-8-hydroxyquinoline was prepared according to literature procedure. ${ }^{20}$

2-[2-Bromo-1-(8-quinolinol-5-yl)-ethylidene]-malononitrile (1). A mixture of 5-acetyl-8-hydroxyquinoline $(18.7 \mathrm{~g}, 100$ mmol), malononitrile (6.6 g, $10 \mathrm{mmol})$ and anhydrous ammonium acetate $(3 \mathrm{~g})$ in dry benzene $(60 \mathrm{ml})$ containing glacial acetic acid $(5 \mathrm{~mL})$ was refluxed for $8 \mathrm{~h}$. The solvent was distilled off in vacuo, the residue was triturated with water $(30 \mathrm{~mL})$, and the organic product was extracted with benzene $(3 \times 50 \mathrm{~mL})$. The benzene layer was dried over anhydrous calcium chloride for $24 \mathrm{~h}$, filtered off, and the solvent was distilled off in vacuo. The solid thus obtained was dissolved in dry benzene $(50 \mathrm{~mL})$ and $N$ bromosuccinimide $(10 \mathrm{mmol})$ of was added. The reaction mixture was refluxed for $4 \mathrm{~h}$. The solvent was evaporated in vacuo. The residue was triturated with ethanol and the solid product was collected by filtration, washed with water, dried over calcium chloride and crystallized from dioxane to afford 1 as yellow crystals in $24 \mathrm{~g} \mathrm{(77 \% )} \mathrm{yield,} \mathrm{m.p.} \mathrm{168-169}$ ${ }^{\circ} \mathrm{C}$. IR: $v=3010$ (CH aromatic), 2950 (CH aliphatic), 2215$2220(\mathrm{CN}), 1630(\mathrm{C}=\mathrm{N}) \mathrm{cm}^{-1}$. ${ }^{1} \mathrm{H}-\mathrm{NMR}$ (DMSO): $\delta=4.4$ $\left(2 \mathrm{H}, \mathrm{s}, \mathrm{CH}_{2}\right), 7.5-8.8(5 \mathrm{H}, \mathrm{m}, \mathrm{ArH}), 9.4(1 \mathrm{H}, \mathrm{s}, \mathrm{OH}$ quinoline) ppm.

2-Amino-4-(8-quinolinol-5-yl)-1-(p-tolyl)-pyrrole-3carbonitrile (2). To a solution of compound 1 (3.14 g, 10 mmol) in $n$-propanol $(30 \mathrm{~mL})$ was added $p$-toluidine $(10.7 \mathrm{~g}$, $10 \mathrm{mmol})$ dissolved in $n$-propanol $(10 \mathrm{~mL})$ dropwise with constant stirring at ambient temperature for $10 \mathrm{~h}$, then kept overnight. The reaction mixture was diluted with water and the solid thus obtained was collected by filtration, dried and crystallized from dioxane to give $\mathbf{2}$ as yellow-orange crystals in $2.75 \mathrm{~g}(81 \%)$ yield, m.p. $239-241{ }^{\circ} \mathrm{C}$. IR: $v=3430,3320$ $\left(\mathrm{NH}_{2}\right), 3050\left(\mathrm{CH}\right.$ aromatic), $2210(\mathrm{CN}), 1625(\mathrm{C}=\mathrm{N}) \mathrm{cm}^{-1}$. ${ }^{1} \mathrm{H}-\mathrm{NMR}\left(\mathrm{CDCl}_{3}\right): \delta=3.1\left(3 \mathrm{H}, \mathrm{s}, \mathrm{CH}_{3}\right), 5.7\left(2 \mathrm{H}, \mathrm{s}, \mathrm{NH}_{2}\right)$ and 7.5-8.8 $(10 \mathrm{H}, \mathrm{m}, \mathrm{ArH}$ and $\mathrm{CH}$ pyrrole $), 9.2(1 \mathrm{H}, \mathrm{s}, \mathrm{OH}$ quinoline) ppm. MS: $m / z=340\left(\mathrm{M}^{+}, 18 \%\right)$.

2-Ethoxymethyleneamino-4-(8-quinolinol-5-yl)-1-( $p$ tolyl)-pyrrole-3-carbonitrile (3). A mixture of 2 (3.4 g, 10 $\mathrm{mmol})$ and ethyl orthoformate $(2 \mathrm{~mL})$ in acetic anhydride $(10 \mathrm{~mL})$ was refluxed for $1 \mathrm{~h}$. After cooling, the precipitated pale yellow crystalline product was filtered off and washed 
thoroughly with ethanol and recrystallized from ethanol to yield 3 as brown crystals in $3.24 \mathrm{~g}(82 \%)$ yield, m.p. 198-199 ${ }^{\circ} \mathrm{C}$. IR: $v=3010(\mathrm{CH}$ aromatic), $2220(\mathrm{CN}), 1630(\mathrm{C}=\mathrm{N})$ $\mathrm{cm}^{-1}$. ${ }^{1} \mathrm{H}-\mathrm{NMR}$ (DMSO): $\delta=1.25\left(3 \mathrm{H}, \mathrm{t}, \mathrm{CH}_{2} \mathrm{CH}_{3}\right), 3.1(3 \mathrm{H}$, s, $\left.\mathrm{CH}_{3}\right), 4.2\left(2 \mathrm{H}, \mathrm{q}, \mathrm{CH}_{2} \mathrm{CH}_{3}\right), 7.5-8.8(10 \mathrm{H}, \mathrm{m}, \mathrm{ArH}$ and $\mathrm{CH}$ pyrrole), $8.9(1 \mathrm{H}, \mathrm{s}, \mathrm{N}=\mathrm{CH}), 9.2(1 \mathrm{H}, \mathrm{s}, \mathrm{OH}$-quinoline) $\mathrm{ppm}$.

3-Amino-4-imino-5-(8-quinolinol-5-yl)-7-(p-tolyl)-3,4dihydropyrrolo $[2,3-d]$ pyrimidine (4). To a suspension of $3(1.98 \mathrm{~g}, 5 \mathrm{mmol})$ in dry benzene $(30 \mathrm{~mL})$, was added hydrazine hydrate $(12 \mathrm{~mL}, 25 \mathrm{mmole})$. The reaction mixture was stirred at room temperature for $7 \mathrm{~h}$. The product was collected and recrystallized from benzene to afford 4 as yellow-orange crystals in $1.41 \mathrm{~g}(74 \%)$ yield, m.p. $>360^{\circ} \mathrm{C}$. IR: $v=3380,3270,3170\left(\mathrm{NH}, \mathrm{NH}_{2}\right), 3010(\mathrm{CH}$ aromatic $)$, $1630(\mathrm{C}=\mathrm{N}) \mathrm{cm}^{-1} .{ }^{1} \mathrm{H}-\mathrm{NMR}(\mathrm{DMSO}): \delta=3.0\left(3 \mathrm{H}, \mathrm{s}, \mathrm{CH}_{3}\right)$, $5.45\left(2 \mathrm{H}, \mathrm{s}, \mathrm{N}-\mathrm{NH}_{2}\right), 7.5-8.8(10 \mathrm{H}, \mathrm{m}, \mathrm{ArH}$ and $\mathrm{CH}$ pyrrole), $8.9(1 \mathrm{H}, \mathrm{s}, \mathrm{C}=\mathrm{NH}), 9.2(1 \mathrm{H}, \mathrm{s}, \mathrm{CH}$ pyrimidine $), 9.4(1 \mathrm{H}, \mathrm{br}$, OH-quinoline) $\mathrm{ppm}$.

2-Diacetylamino-4-(8-quinolinol-5-yl)-1-(p-tolyl)-pyrrole3-carbonitrile (5). A mixture of $2(1.7 \mathrm{~g}, 5 \mathrm{mmol})$ and acetic anhydride $(10 \mathrm{~mL})$ was heated under reflux for $4 \mathrm{~h}$. The reaction mixture was cooled and poured into cold water. The precipitate formed filtered off, washed with water, dried and crystallized from ethanol to give $\mathbf{5}$ as pale brown crystals in $1.63 \mathrm{~g}(77 \%)$ yield, m.p. $178-179{ }^{\circ} \mathrm{C}$. IR: $v=3050(\mathrm{CH}$ aromatic), $2210(\mathrm{CN}), 1730(\mathrm{CO}) \mathrm{cm}^{-1} .{ }^{1} \mathrm{H}-\mathrm{NMR}\left(\mathrm{CF}_{3} \mathrm{COOD}\right)$ : $\delta=2.95\left(3 \mathrm{H}, \mathrm{s}, \mathrm{CH}_{3}\right), 3.5\left(6 \mathrm{H}, \mathrm{s}, 2 \mathrm{COCH}_{3}\right), 7.4-8.8(10 \mathrm{H}$, $\mathrm{m}, \mathrm{ArH}$ and $\mathrm{CH}$ pyrrole) ppm.

2-Methyl-5-(8-quinolinol-5-yl)-7-(p-tolyl)-pyrrolo[2,3- $d$ ] pyrimidine-4(3H)-one (6). A solution of $2(1.7 \mathrm{~g}, 5 \mathrm{mmol})$ in acetic anhydride-pyridine mixture $(30 \mathrm{~mL}, 2: 1 \mathrm{v} / \mathrm{v})$ was heated on a water bath for $8 \mathrm{~h}$, then cooled and poured into ice / water mixture. The precipitate thus formed was filtered off, washed several times with water, dried and crystallized from acetic acid to yield 6 as yellowish crystals in $1.31 \mathrm{~g}$ (69\%) yield, m.p. $252-254^{\circ} \mathrm{C}$. IR: $v=3100(\mathrm{NH}), 3050(\mathrm{CH}$ aromatic), $1660(\mathrm{CO}) \mathrm{cm}^{-1} .{ }^{1} \mathrm{H}-\mathrm{NMR}\left(\mathrm{CF}_{3} \mathrm{COOD}\right): \delta=2.8$ $\left(3 \mathrm{H}, \mathrm{s}, \mathrm{CH}_{3}\right), 2.95\left(3 \mathrm{H}, \mathrm{s}, \mathrm{CH}_{3}\right), 7.4-8.7(10 \mathrm{H}, \mathrm{m}, \mathrm{ArH}$ and $\mathrm{CH}$ pyrrole )ppm.

4-Amino-5-(8-quinolinol-5-yl)-7-(p-tolyl)-pyrrolo[2,3-d] pyrimidine (7). A mixture of $2(1.7 \mathrm{~g}, 5 \mathrm{mmol})$ and formamide $(20 \mathrm{~mL})$ was refluxed for $1 \mathrm{~h}$. After cooling, the reaction mixture was poured into cold water. The solid precipitate was filtered, washed with water, dried and recrystallized from dioxane to give 7 as yellow crystals in 1.18 g $(65 \%)$ yield, m.p. $330-332{ }^{\circ} \mathrm{C} . \mathrm{IR}: v=3420,3330$ $\left(\mathrm{NH}_{2}\right), 3010\left(\mathrm{CH}\right.$ aromatic), $1630(\mathrm{C}=\mathrm{N}) \mathrm{cm}^{-1} .{ }^{1} \mathrm{H}-\mathrm{NMR}$ (DMSO): $\delta=2.95\left(3 \mathrm{H}, \mathrm{s}, \mathrm{CH}_{3}\right), 5.60\left(2 \mathrm{H}, \mathrm{s}, \mathrm{NH}_{2}\right), 7.5-8.9$ (10H,m, ArH and $\mathrm{CH}$ pyrrole), 9.2 (1H, s, CH pyrimidine), $9.45(1 \mathrm{H}, \mathrm{s}, \mathrm{OH}$ quinoline) $\mathrm{ppm}$.

2-Amino-4-(8-quinolinol-5-yl)-1-(p-tolyl)-3-(4,5-dihydro$\mathbf{1 H}$-imidazol-2-yl) -pyrrole (8). To a mixture of $2(1.7 \mathrm{~g}, 5$ $\mathrm{mmol}$ ) and ethylenediamine $(7.5 \mathrm{~mL})$ was added dropwise carbon disulfide $(0.7 \mathrm{~mL})$. The reaction mixture was heated under reflux for $4 \mathrm{~h}$. After cooling the reactiom mixture was poured into cold water and the precipitate obtained was filtered off, washed with water, dried and crystallized from ethanol to yield 8 as yellow-orange crystals in $1.5 \mathrm{~g} \mathrm{(79 \% )}$ yield, m.p. $243-245{ }^{\circ} \mathrm{C}$. IR: $v=3420-3245\left(\mathrm{NH}_{2}, \mathrm{NH}\right) \mathrm{cm}^{-1}$. ${ }^{1} \mathrm{H}-\mathrm{NMR}$ (DMSO): $\delta=2.95\left(3 \mathrm{H}, \mathrm{s}, \mathrm{CH}_{3}\right), 3.5\left(2 \mathrm{H}, \mathrm{t}, \mathrm{CH}_{2}\right.$ imidazoline), $4.1\left(2 \mathrm{H}, \mathrm{t}, \mathrm{CH}_{2}\right.$ imidazoline), $5.97(2 \mathrm{H}, \mathrm{s}$, $\left.\mathrm{NH}_{2}\right), 7.4-8.9(10 \mathrm{H}, \mathrm{m}, \mathrm{ArH}$ and $\mathrm{CH}$ pyrrole $), 9.15(1 \mathrm{H}, \mathrm{s}$, $\mathrm{NH}), 9.25(1 \mathrm{H}, \mathrm{s}, \mathrm{OH}$ quinoline) $\mathrm{ppm}$.

2-( $\alpha$-Chloroacetamido)-4-(8-quinolinol-5-yl)-1-(p-tolyl)pyrrole-3-carbonitrile (9). To a solution of $2(1.7 \mathrm{~g}, 5$ $\mathrm{mmol})$ in dioxane $(30 \mathrm{~mL})$, chloroacetyl chloride $(1.13 \mathrm{~g}$, $0.01 \mathrm{~mol}$ ) was added dropwise with stirring at room temperature. The reaction mixture was heated under reflux for $30 \mathrm{~min}$. at $60{ }^{\circ} \mathrm{C}$, left at room temperature overnight and poured onto cold water. The solid product obtained was collected by filtration and crystallized from ethanol to afford 9 as pale brown crystals in $1.2 \mathrm{~g}(58 \%)$ yield, m.p. 190-192 ${ }^{\circ} \mathrm{C}$. IR: $v=3250(\mathrm{NH}), 2210(\mathrm{CN}), 1700(\mathrm{CO}) \mathrm{cm}^{-1} \cdot{ }^{1} \mathrm{H}-$ NMR (DMSO): $\delta=2.99\left(\mathrm{~s}, 3 \mathrm{H}, \mathrm{CH}_{3}\right), 4.35\left(2 \mathrm{H}, \mathrm{s}, \mathrm{CH}_{2}\right), 7.6-$ $8.7(10 \mathrm{H}, \mathrm{m}, \mathrm{ArH}$ and $\mathrm{CH}$ pyrrole $), 8.90(1 \mathrm{H}, \mathrm{s}, \mathrm{NH}), 9.2$ $(1 \mathrm{H}, \mathrm{br}, \mathrm{CH}$ quinoline) $\mathrm{ppm}$.

9-(8-Quinolinol-5-yl)-7-(p-tolyl)-pyrrolo[3,2-e]-1,2,4triazolo[1,5-c]pyrimidine, 9-(8-Quinolinol-5-yl)-7-( $p$-tolyl)2-methylpyrrolo[3,2-e]-1,2,4-triazolo[1,5-c]pyrimidine and 9-(8-Quinolinol-5-yl)-7-(p-tolyl)-2-chloromethylpyrrolo[3,2$e]-1,2,4$-triazolo[1,5-c]pyrimidine (10a-c).

General Procedure: A mixture of $4(3.82 \mathrm{~g}, 10 \mathrm{mmol})$, triethyl orthoformate, acetyl chloride and/or chloroacetyl chloride $(10 \mathrm{mmol})$ in benzene $(30 \mathrm{~mL})$ was refluxed for $5 \mathrm{~h}$. The obtained solid was collected and recrystallized from benzene to afford 10a-c in $64-71 \%$ yield as yellowish crystals. 10a (64\% yield); m.p. $260-261{ }^{\circ} \mathrm{C}$. IR: $v=3010$ (CH aromatic), $1616(\mathrm{C}=\mathrm{N}), 1540(\mathrm{C}=\mathrm{C}) \mathrm{cm}^{-1} .{ }^{1} \mathrm{H}-\mathrm{NMR}$ (DMSO): $\delta=2.95\left(3 \mathrm{H}, \mathrm{s}, \mathrm{CH}_{3}\right), 7.5-8.4(10 \mathrm{H}, \mathrm{m}, \mathrm{ArH}$ and $\mathrm{CH}$ pyrrole), $8.6(1 \mathrm{H}, \mathrm{s}, \mathrm{CH}$ triazole), 8.9-9.1 $(2 \mathrm{H}, 2 \mathrm{~s}, \mathrm{CH}$ pyrimidine $\mathrm{OH}$ and quinoline) $\mathrm{ppm}$. MS: $\mathrm{m} / z=392\left(\mathrm{M}^{+}\right.$, 9.2). $10 \mathrm{~b}\left(65 \%\right.$ yield); m.p. $277-279{ }^{\circ} \mathrm{C}$. IR: $v=3010(\mathrm{CH}$ aromatic), $2995(\mathrm{CH}$ aliphatic $), 1616(\mathrm{C}=\mathrm{N}), 1540(\mathrm{C}=\mathrm{C})$ $\mathrm{cm}^{-1} .{ }^{1} \mathrm{H}-\mathrm{NMR}$ (DMSO): $\delta=2.2\left(3 \mathrm{H}, \mathrm{s}, \mathrm{CH}_{3}\right), 2.95(3 \mathrm{H}, \mathrm{s}$, $\left.\mathrm{CH}_{3}\right), 7.5-8.4(10 \mathrm{H}, \mathrm{m}, \mathrm{ArH}$ and $\mathrm{CH}$ pyrrole), 8.9-9.1 $(2 \mathrm{H}, 2 \mathrm{~s}$, $\mathrm{CH}$ pyrimidine and $\mathrm{OH}$ quinoline) ppm. 10c (71\% yield); m.p. $225-227{ }^{\circ} \mathrm{C}$. IR: $v=3010$ (CH aromatic), $2995(\mathrm{CH}$ aliphatic), $1610(\mathrm{C}=\mathrm{N}) \mathrm{cm}^{-1} .{ }^{1} \mathrm{H}-\mathrm{NMR}$ (DMSO): $\delta=2.95$ $\left(3 \mathrm{H}, \mathrm{s}, \mathrm{CH}_{3}\right), 5.1\left(2 \mathrm{H}, \mathrm{s}, \mathrm{CH}_{2}\right) 7.5-8.4(10 \mathrm{H}, \mathrm{m}, \mathrm{ArH}$ and $\mathrm{CH}$ pyrrole), 9.0-9.2 (2H, 2s, $\mathrm{CH}$ pyrimidine $\mathrm{OH}$ and quinoline).

9-(8-Quinolinol-5-yl)-7-(p-tolyl)-2-Cyanomethylpyrrolo [3,2-e]-1,2,4-triazolo[1,5-c]pyrimidine (10d). A mixture of $4(1.9 \mathrm{~g}, 5 \mathrm{mmol})$ and ethyl cyanoacetate $(5 \mathrm{mmol})$ in absolute ethanol $(50 \mathrm{~mL})$ was refluxed for $8 \mathrm{~h}$. After cooling the obtained solid product was filtered off and recrystallized from dioxane to give 10d as orange crystals in $1.39 \mathrm{~g}(65 \%$ yield), m.p. $283-285{ }^{\circ} \mathrm{C}$. IR: $v=2950$ (CH aliphatic), 2230 (CN) $\mathrm{cm}^{-1} .{ }^{1} \mathrm{H}-\mathrm{NMR}$ (DMSO): $\delta=3.1\left(3 \mathrm{H}, \mathrm{s}, \mathrm{CH}_{3}\right), 4.55$ (2H, s, $\left.\mathrm{CH}_{2}\right), 7.5-8.4$ (10H, m, ArH and $\mathrm{CH}$ pyrrole), 8.9-9.1 $(2 \mathrm{H}, 2 \mathrm{~s}, \mathrm{CH}$ pyrimidine and $\mathrm{OH}$ quinoline) $\mathrm{ppm}$.

3-Amino-4-(8-quinolinol-5-yl)-6-( $p$-tolyl)-1 $H$-pyrrolo [2,3-c]pyrazole (11). A mixture of $2(3.4 \mathrm{~g}, 10 \mathrm{mmol})$ and hydroxylamine hydrochloride $(0.60 \mathrm{~g}, 10 \mathrm{mmol})$ in glacial acetic acid $(30 \mathrm{~mL})$ containing anhydrous sodium acetate (1 
g) was boiled under reflux for $5 \mathrm{~h}$. The reaction mixture was left overnight at room temperature and then poured onto water. The solid precipitate was filtered off, washed with water, and crystallized from dioxane to yield $\mathbf{1 1}$ as pale yellow crystals in $2.2 \mathrm{~g}$ (62\% yield), m.p. $312-313^{\circ} \mathrm{C}$. IR: $v$ $=3470-3250\left(\mathrm{NH}, \mathrm{NH}_{2}\right), 2950(\mathrm{CH}$ aliphatic $) \mathrm{cm}^{-1} .{ }^{1} \mathrm{H}-\mathrm{NMR}$ (DMSO): $\delta=2.95\left(3 \mathrm{H}, \mathrm{s}, \mathrm{CH}_{3}\right), 6.30\left(2 \mathrm{H}, \mathrm{s}, \mathrm{NH}_{2}\right), 7.5-8.4$ $(10 \mathrm{H}, \mathrm{m}, \mathrm{ArH}$ and $\mathrm{CH}$ pyrrole), $8.77(1 \mathrm{H}, \mathrm{s}, \mathrm{NH}), 9.25(1 \mathrm{H}$, br, $\mathrm{OH}$ quinoline) ppm. MS: $m / z=353\left(\mathrm{M}^{+}-2,5.7 \%\right)$.

3-Benzylideneamino-4-(8-quinolinol-5-yl)-6-(p-tolyl)$1 \boldsymbol{H}$-pyrrolo[2,3-c]pyrazole (12). A suspension of 11 (1.75 g, $5 \mathrm{mmol})$ and benzaldehyde $(0.5 \mathrm{~mL}, 5 \mathrm{mmol})$ in dioxane containing a few drops of piperidine $(30 \mathrm{~mL})$ was boiled under reflux for $5 \mathrm{~h}$. Then the solvent was evaporated in vacuo. The reaction mixture was triturated with cold water; the solid product was filtered off and crystallized from dioxane to give $\mathbf{1 2}$ as yellow crystals in $1.12 \mathrm{~g}$ (51\% yield), m.p. $340-342{ }^{\circ} \mathrm{C}$. IR: $v=3200(\mathrm{NH}), 1620(\mathrm{C}=\mathrm{N}) \mathrm{cm}^{-1} .{ }^{1} \mathrm{H}-$ NMR (DMSO): $\delta=2.95\left(3 \mathrm{H}, \mathrm{s}, \mathrm{CH}_{3}\right), 7.3-8.7(15 \mathrm{H}, \mathrm{m}, \mathrm{ArH}$ and $\mathrm{CH}$ pyrrole), $8.9(1 \mathrm{H}, \mathrm{s}, \mathrm{NH}), 9.2-9.3(2 \mathrm{H}, \mathrm{m}, \mathrm{N}=\mathrm{CH}$ and $\mathrm{OH}$ quinoline) ppm.

5,7-Dimethyl-3-(8-quinolinol-5-yl)-1-(p-tolyl)-pyrimido $\left[\mathbf{1}^{\prime}, \mathbf{2}^{\prime}: \mathbf{1 , 5}\right]$ pyrazolo[3,4-b]pyrrole (13). To a mixture of 11 $(1.75 \mathrm{~g}, 5 \mathrm{mmol})$, acetylacetone $(0.5 \mathrm{~mL}, 5 \mathrm{mmol})$ and ethanol $(25 \mathrm{~mL})$, a few drops of acetic acid were added. The reaction mixture was refluxed for $5 \mathrm{~h}$, then concentrated and allowed to cool. The precipitate that formed was collected and recrystallized from ethanol to yield $\mathbf{1 3}$ as yellow-orange crystals in $1.5 \mathrm{~g}(53 \%)$ yield, m.p. $265-267^{\circ} \mathrm{C}$. IR: $v=1620$ $(\mathrm{C}=\mathrm{N}), 1580(\mathrm{C}=\mathrm{C}) \mathrm{cm}^{-1} .{ }^{1} \mathrm{H}-\mathrm{NMR}\left(\mathrm{CF}_{3} \mathrm{COOD}\right): \delta=2.95$ $\left(3 \mathrm{H}, \mathrm{s}, \mathrm{CH}_{3}\right), 3.1\left(3 \mathrm{H}, \mathrm{s}, \mathrm{CH}_{3}\right), 3.3\left(3 \mathrm{H}, \mathrm{s}, \mathrm{CH}_{3}\right), 7.3-8.7(10 \mathrm{H}$, $\mathrm{m}, \mathrm{ArH}$ and $\mathrm{CH}$ pyrrole), 8.9 (1H, s, CH pyrimidine) ppm.

5-Methyl-3-(8-quinolinol-5-yl)-1-(p-tolyl)-pyrimido $[1 ', 2 '$ : 1,5]pyrazolo[3,4-b]pyrrole-7(4H)-one (14). A mixture of 11 (1.75 g, $5 \mathrm{mmol})$, ethyl acetoacetate $(0.65 \mathrm{~mL}, 5 \mathrm{mmol})$ and glacial acetic acid $(20 \mathrm{~mL})$ was refluxed for $5 \mathrm{~h}$. The solid product that formed after cooling was collected and recrystallized from ethanol to yield 14 as pale brown crystals in $1.02 \mathrm{~g}(49 \%)$ yield, m.p. $>360{ }^{\circ} \mathrm{C}$. IR: $v=1680$ (CO), $1630(\mathrm{C}=\mathrm{N}), 1580(\mathrm{C}=\mathrm{C}) \mathrm{cm}^{-1} .{ }^{1} \mathrm{H}-\mathrm{NMR}$ (DMSO): $\delta=$ $2.90\left(3 \mathrm{H}, \mathrm{s}, \mathrm{CH}_{3}\right), 3.2\left(3 \mathrm{H}, \mathrm{s}, \mathrm{CH}_{3}\right), 7.1-8.5(10 \mathrm{H}, \mathrm{m}, \mathrm{ArH}$ and $\mathrm{CH}$ pyrrole), 9.1 (1H, s, CH pyrimidine), $9.35(1 \mathrm{H}, \mathrm{s}, \mathrm{OH}$ quinoline) ppm.

1[4-(8-Quinolinol-5-yl)-6-(p-tolyl)-1H-pyrrolo[2,3-c] pyrazol-3-yl)-3-phenylthiourea (15). A mixture of 11 (1.75 $\mathrm{g}, 5 \mathrm{mmol})$, phenyl isothiocyanate $(0.66 \mathrm{~mL}, 5 \mathrm{mmol})$ and pyridine $(30 \mathrm{~mL})$ was refluxed for $3 \mathrm{~h}$. The precipitate that formed was collected and recrystallized from dioxane to give 15 as yellow crystals in $1.39 \mathrm{~g}(57 \%)$ yield m.p. $280-282^{\circ} \mathrm{C}$. IR: $v=3450,3350(2 \mathrm{NH}), 1240(\mathrm{C}=\mathrm{S}) \mathrm{cm}^{-1}$. ${ }^{1} \mathrm{H}-\mathrm{NMR}$ ( $\left.\mathrm{CF}_{3} \mathrm{COOD}\right): \delta=2.95$ (3H, s, $\left.\mathrm{CH}_{3}\right), 7.1-8.8(15 \mathrm{H}, \mathrm{m}, \mathrm{ArH}$ and $\mathrm{CH}$ pyrrole) ppm. MS: $m / z=490\left(\mathrm{M}^{+}, 13.2 \%\right)$.

4-Amino-3-(8-quinolinol-5-yl)-1 -(p-tolyl)-8-oxo-7,8dihydropyrrolo[1,2-a]pyrrolo[2,3-e]pyrimidine-6-carbonitrile (17). To a solution of $9(2.08 \mathrm{~g}, 5 \mathrm{mmol})$ in dioxane $(30 \mathrm{~mL})$ containing a catalytic amount of triethyl amine $(0.5 \mathrm{~mL})$, malononitrile $(0.33 \mathrm{~g}, 5 \mathrm{mmol})$ was added. The reaction mixture was heated under reflux for $4 \mathrm{~h}$, cooled to room temperature, poured onto cold water and neutralized with dilute hydrochloric acid. The solid product precipitated was collected by filtration, dried and crystallized from dioxane to yield 17 as yellow crystals in $1.09 \mathrm{~g}(49 \%)$ yield, m.p. 189$190^{\circ} \mathrm{C}$. IR: $v=3450,3345\left(\mathrm{NH}_{2}\right), 2216(\mathrm{CN})$ and $1735(\mathrm{CO})$ $\mathrm{cm}^{-1} .{ }^{1} \mathrm{H}-\mathrm{NMR}$ (DMSO): $\delta=2.95\left(3 \mathrm{H}, \mathrm{s}, \mathrm{CH}_{3}\right), 4.15(2 \mathrm{H}, \mathrm{s}$, $\left.\mathrm{CH}_{2}\right), 7.3-8.8(10 \mathrm{H}, \mathrm{m}, \mathrm{ArH}$ and $\mathrm{CH}$ pyrrole), $8.95(1 \mathrm{H}, \mathrm{s}$, $\mathrm{CH}$ pyrimidine), 9.15 (1H, br, $\mathrm{OH}$ quinoline) $\mathrm{ppm}$.

7-(p-Tolyl)-9-(8-quinolinol-5-yl)-2,3-dihydroimidazo [1,2-c]pyrrolo[3,2-e]pyrimidine (18). A mixture of 8 (1.91 $\mathrm{g}, 5 \mathrm{mmol})$ and triethyl orthoformate $(15 \mathrm{~mL})$ was heated under reflux for $3 \mathrm{~h}$. After cooling, the reaction mixture was poured into cold water. The solid precipitate was filtered off, washed with water, dried and recrystallized from dioxane to give 18 as pale brown crystals in $0.99 \mathrm{~g}(51 \%)$ yield, m.p. $>360{ }^{\circ} \mathrm{C}$. IR: $v=3010$ (CH aromatic), 2995 (CH aliphatic), $1630(\mathrm{C}=\mathrm{N}) \mathrm{cm}^{-1} .{ }^{1} \mathrm{H}-\mathrm{NMR}$ (DMSO): $\delta=2.95\left(3 \mathrm{H}, \mathrm{s}, \mathrm{CH}_{3}\right)$, 4.15 (2H, t, $\mathrm{CH}_{2}$ imidazoline), $4.2\left(2 \mathrm{H}, \mathrm{t}, \mathrm{CH}_{2}\right.$ imidazoline), 7.4-8.8 (10H, m, ArH and $\mathrm{CH}$ pyrrole), 9.15 (1H, s, CH pyrimidine), 9.35 (1H, s, OH quinoline) ppm.

7-(p-Tolyl)-9-(8-quinolinol-5-yl)-5-methyl (phenyl)-2,3dihydroimidazo[1,2-c]pyrrolo[3,2-e]pyrimidine $(19,20)$.

General procedure: A mixture of $8(1.91 \mathrm{~g}, 5 \mathrm{mmol})$, acetyl and/or benzoyl chloride $(5 \mathrm{mmol})$ in pyridine $(20 \mathrm{~mL})$ was heated under reflux for $6 \mathrm{~h}$. The reaction mixture was then cooled and poured into water. The solid precipitate formed after standing for $1 \mathrm{~h}$ was filtered, washed with water, dried and recrystallized from acetic acid to give 19 and 20 , in 55 and $61 \%$ yield, respectively as yellow crystals. 19 (55\% yield), m.p. $319-321{ }^{\circ} \mathrm{C}$. IR: $v=3050(\mathrm{CH}$ aromatic), 2995 (CH aliphatic), $1630(\mathrm{C}=\mathrm{N}) \mathrm{cm}^{-1}$. ${ }^{1} \mathrm{H}-\mathrm{NMR}$ $\left(\mathrm{CF}_{3} \mathrm{COOD}\right): \delta=2.99\left(3 \mathrm{H}, \mathrm{s}, \mathrm{CH}_{3}\right), 3.2\left(3 \mathrm{H}, \mathrm{s}, \mathrm{CH}_{3}\right), 4.1$ (2H, t, $\mathrm{CH}_{2}$ imidazoline), 4.5 (2H, t, $\mathrm{CH}_{2}$ imidazoline), 7.4$8.8(10 \mathrm{H}, \mathrm{m}, \mathrm{ArH}$ and $\mathrm{CH}$ pyrrole $)$ ppm.. MS: $m / z=407$ $\left(\mathrm{M}^{+}, 10.8 \%\right) .20$ (61\% yield), m.p. $352-354{ }^{\circ} \mathrm{C}$. IR: $v=3050$ (CH aromatic), 2995 (CH aliphatic), $1630(\mathrm{C}=\mathrm{N}) \mathrm{cm}^{-1} \cdot{ }^{1} \mathrm{H}-$ NMR (DMSO): $\delta=3.8$ (2H, t, $\mathrm{CH}_{2}$ imidazoline), $4.2(2 \mathrm{H}, \mathrm{t}$, $\mathrm{CH}_{2}$ imidazoline), 7.5-8.9 (15H, m, ArH and $\mathrm{CH}$ pyrrole), 9.25 (1H, br, OH quinoline) ppm.

7-(p-Tolyl)-9-(8-quinolinol-5-yl)-2,3,6-trihydroimidazo [1,2-c]pyrrolo[3,2-e]pyrimidine-5(6H)-thione (21). A mixture of $8(1.91 \mathrm{~g}, 5 \mathrm{mmol})$ and carbon disulfide $(15 \mathrm{~mL})$ in dry pyridine $(50 \mathrm{~mL})$ was heated under reflux for $10 \mathrm{~h}$. The solid product formed on hot was filtered, washed with water, dried and crystallized from dioxane-water $(2: 1)$ to afford 21 as yellowish crystals in $1.4 \mathrm{~g}(67 \%)$ yield, m.p. $>360{ }^{\circ} \mathrm{C}$. IR: $v=$ $3150(\mathrm{NH}), 1600(\mathrm{C}=\mathrm{N}) \mathrm{cm}^{-1}$. ${ }^{1} \mathrm{H}-\mathrm{NMR}(\mathrm{DMSO}): \delta=2.95$ ( $\left.3 \mathrm{H}, \mathrm{s}, \mathrm{CH}_{3}\right), 3.5\left(2 \mathrm{H}, \mathrm{t}, \mathrm{CH}_{2}\right.$ imidazoline), $4.1\left(2 \mathrm{H}, \mathrm{t}, \mathrm{CH}_{2}\right.$ imidazoline), 7.5-8.9 (10H, m, ArH and $\mathrm{CH}$ pyrrole), 9.25 (1H, br, OH quinoline) ppm. MS: $m / z=425\left(\mathrm{M}^{+}, 19.2 \%\right)$.

7-(p-Tolyl)-9-(8-quinolinol-5-yl)-2,3-dihydroimidazo [1,2-c]pyrrolo[3,2-e]pyrimidine-5-ethylthio; Ethyl [7-(ptolyl)-9-(8-quinolinol-5-yl)-2,3-dihydroimidazo[1,2-c] pyrrolo [3,2-e]pyrimidine-5-yl]-thioacetate and 7-(p-Tolyl)-9-(8quinolinol-5-yl)-2,3-dihydro-5-benzoylmethylthio imidazo [1,2-c]pyrrolo[3,2-e]pyrimidine (22-24). 
General procedure: A mixture of $21(0.425 \mathrm{~g}, 1 \mathrm{mmol})$, the appropriate halo derivative (ethyl iodide, ethyl chloroacetate, phenacyl bromide) $(1 \mathrm{mmol})$ and sodium acetate $(0.6 \mathrm{~g})$ in ethanol $(40 \mathrm{~mL})$ was heated under reflux for $3 \mathrm{~h}$. The reaction mixture was then cooled and poured into water. The solid precipitate was filtered off, washed with water, dried and recrystallized from ethanol to give 22-24 in 57$67 \%$ yield as wellowish crystals. 22 (57\% yield), m.p. 257-259 ${ }^{\circ} \mathrm{C}$. IR: $v=3010$ (CH aromatic), 2990 (CH aliphatic), 1635 $(\mathrm{C}=\mathrm{N}) \mathrm{cm}^{-1} .{ }^{1} \mathrm{H}-\mathrm{NMR}(\mathrm{DMSO}): \delta=1.2\left(3 \mathrm{H}, \mathrm{t}, \mathrm{SCH}_{2} \mathrm{CH}_{3}\right)$, $3.0\left(3 \mathrm{H}, \mathrm{s}, \mathrm{CH}_{3}\right), 3.2\left(2 \mathrm{H}, \mathrm{q}, \mathrm{SCH}_{2} \mathrm{CH}_{3}\right), 3.5\left(2 \mathrm{H}, \mathrm{t}, \mathrm{CH}_{2}\right.$ imidazoline), $3.9\left(2 \mathrm{H}, \mathrm{t}, \mathrm{CH}_{2}\right.$ imidazoline $), 7.58 .9(10 \mathrm{H}, \mathrm{m}$, ArH and $\mathrm{CH}$ pyrrole), 9.2 (1H, s, OH quinoline) ppm. 23 (61\% yield), m.p. $247-248{ }^{\circ} \mathrm{C}$. IR: $v=3050(\mathrm{CH}$ aromatic), $1730(\mathrm{CO}) \mathrm{cm}^{-1} \cdot{ }^{1} \mathrm{H}-\mathrm{NMR}$ (DMSO): $\delta=1.4(3 \mathrm{H}, \mathrm{t}$, $\left.\mathrm{CH}_{2} \mathrm{CH}_{3}\right), 2.95$ (3H, s, $\left.\mathrm{CH}_{3}\right), 3.5$ (2H, t, $\mathrm{CH}_{2}$ imidazoline), $3.9\left(2 \mathrm{H}, \mathrm{t}, \mathrm{CH}_{2}\right.$ imidazoline), $4.7\left(2 \mathrm{H}, \mathrm{q}, \mathrm{CH}_{2} \mathrm{CH}_{3}\right), 5.3(2 \mathrm{H}$, s, $\left.\mathrm{SCH}_{2}\right), 7.5-8.9(10 \mathrm{H}, \mathrm{m}, \mathrm{ArH}$ and $\mathrm{CH}$ pyrrole $), 9.25(1 \mathrm{H}$, s, OH quinoline) ppm. 24 (67\% yield), m.p. $287-288^{\circ} \mathrm{C}$. IR: $v=3060$ (CH aromatic), 2995 (CH aliphatic), 1680 (CO), $1600(\mathrm{C}=\mathrm{N}) \mathrm{cm}^{-1} .{ }^{1} \mathrm{H}-\mathrm{NMR}$ (DMSO): $\delta=3.1\left(3 \mathrm{H}, \mathrm{s}, \mathrm{CH}_{3}\right), 3.7$ ( $2 \mathrm{H}, \mathrm{t}, \mathrm{CH}_{2}$ imidazoline), 4.1 (2H, t, $\mathrm{CH}_{2}$ imidazoline), 5.35 (2H, s, $\left.\mathrm{SCH}_{2} \mathrm{COPh}\right), 7.5-8.9$ (15H, m, ArH and $\mathrm{CH}$ pyrrole), $9.15(1 \mathrm{H}, \mathrm{s}, \mathrm{OH}$ quinoline $) \mathrm{ppm}$.

7-(p-Tolyl)-9-(8-quinolinol-5-yl)-2,3-dihydroimidazo [1,2-c]pyrrolo[3,2-e]-1,2,3-triazine (25). To a cold solution of $8(1.91 \mathrm{~g}, 5 \mathrm{mmol})$ in conc. hydrochloric acid $(15 \mathrm{ml})$ and acetic acid $(15 \mathrm{~mL})$ was added a solution of sodium nitrite $(2$ $\mathrm{g})$ in water $(15 \mathrm{~mL})$. After completion of the addition (30 $\mathrm{min}$ ), the ice bath was removed and stirring was continued for $2 \mathrm{~h}$. The solid product was filtered off and recrystallized from dioxane to afford $\mathbf{2 5}$ as deep brown crystals in $1.3 \mathrm{~g}$ (67\%) yield, m.p. $>360{ }^{\circ} \mathrm{C}$. IR: $v=1600,1620(\mathrm{~N}=\mathrm{N}, \mathrm{C}=\mathrm{N})$ $\mathrm{cm}^{-1}$. ${ }^{1} \mathrm{H}-\mathrm{NMR}$ (DMSO): $\delta=2.95\left(3 \mathrm{H}, \mathrm{s}, \mathrm{CH}_{3}\right), 3.5(2 \mathrm{H}, \mathrm{t}$, $\mathrm{CH}_{2}$ imidazoline), $4.0\left(2 \mathrm{H}, \mathrm{t}, \mathrm{CH}_{2}\right.$ imidazoline), 7.5-8.9 $(10 \mathrm{H}, \mathrm{m}, \mathrm{ArH}$ and $\mathrm{CH}$ pyrrole), $9.15(1 \mathrm{H}, \mathrm{s}, \mathrm{OH}$ quinoline $)$ ppm.

4-Chloro-5-(8-quinolinol-5-yl)-7-(p-tolyl)-2-methylpyrrolo [2,3- $d$ ]pyrimidine (26). A sample of 6 (3.82 $\mathrm{g}, 10 \mathrm{mmol})$ was refluxed in phosphorus oxychloride $(20 \mathrm{~mL})$ on a hot plate for $2 \mathrm{~h}$. The reaction mixture was cooled and diluted with ice cooled water. The resulting precipitate was filtered off, washed thoroughly with water, dried and crystallized from chloroform to afford $\mathbf{2 6}$ as gray plates in $2.36 \mathrm{~g}(59 \%)$ yield, m.p. $248-250{ }^{\circ} \mathrm{C}$. IR: $v=3050(\mathrm{CH}$ aromatic $), 1630(\mathrm{C}=\mathrm{N})$ $\mathrm{cm}^{-1}$. ${ }^{1} \mathrm{H}-\mathrm{NMR}$ (DMSO): $\delta=2.9\left(3 \mathrm{H}, \mathrm{s}, \mathrm{CH}_{3}\right), 3.15(3 \mathrm{H}, \mathrm{s}$, $\left.\mathrm{CH}_{3}\right), 7.4-8.8(10 \mathrm{H}, \mathrm{m}, \mathrm{ArH}$ and $\mathrm{CH}$ pyrrole $), 9.20(1 \mathrm{H}, \mathrm{s}$, $\mathrm{OH}$ quinoline) $\mathrm{ppm}$.

4-Hydrazino-5-(8-quinolinol-5-yl)-7-(p-tolyl)-2-methylpyrrolo [2,3-d] pyrimidine (27). A mixture of $26(2.1 \mathrm{~g} 5 \mathrm{mmol})$ and hydrazine hydrate $(0.6 \mathrm{~mL})$ in ethanol $(30 \mathrm{~mL})$ was heated at $90{ }^{\circ} \mathrm{C}$ for $6 \mathrm{~h}$. The precipitate resulting after cooling was collected by filtration and crystallized from dioxane to yield 27 as yellowish crystals in $1.5 \mathrm{~g}(76 \%)$ yield, m.p. $318-320$ ${ }^{\circ} \mathrm{C}$. IR: $v=3400-3150\left(\mathrm{NHNH}_{2}\right) \mathrm{cm}^{-1}$. ${ }^{1} \mathrm{H}-\mathrm{NMR}$ (DMSO) $2.95\left(3 \mathrm{H}, \mathrm{s}, \mathrm{CH}_{3}\right), 3.2\left(3 \mathrm{H}, \mathrm{s}, \mathrm{CH}_{3}\right), 3.9\left(2 \mathrm{H}, \mathrm{s}, \mathrm{NH}_{2}\right), 7.4-$ $8.8(10 \mathrm{H}, \mathrm{m}, \mathrm{ArH}$ and $\mathrm{CH}$ pyrrole $)), 9.1(1 \mathrm{H}, \mathrm{s}, \mathrm{NH}), 9.25$
(1H, br, OH quinoline) ppm.

4-Azido-5-(8-quinolinol-5-yl)-7-(p-tolyl)-2-methylpyrrolo [2,3- $d$ ]pyrimidine (28). To a cold solution of $27(0.79 \mathrm{~g}, 3$ $\mathrm{mmol})$ in acetic acid $(20 \mathrm{~mL})$ was added a solution of sodium nitrite $(2 \mathrm{~g})$ in water $(10 \mathrm{~mL})$. After completion of addition (30 $\mathrm{min}$ ), the ice bath was removed and stirring was continued for $1 \mathrm{~h}$. The solid product was filtered off and recrystallized from ethanol to afford $\mathbf{2 8}$ as yellow crystals in $0.47 \mathrm{~g}(58 \%)$ yield, m.p. $318-320{ }^{\circ} \mathrm{C}$. IR: $v=2130\left(\mathrm{~N}_{3}\right)$, $1630(\mathrm{C}=\mathrm{N}) \mathrm{cm}^{-1}$. ${ }^{1} \mathrm{H}-\mathrm{NMR}\left(\mathrm{CF}_{3} \mathrm{COOD}\right) 2.95\left(3 \mathrm{H}, \mathrm{s}, \mathrm{CH}_{3}\right)$, 7.4-8.6 (10H, m, ArH and $\mathrm{CH}$ pyrrole) $\mathrm{ppm}$.

7-(p-Tolyl)-9-(8-quinolinol-5-yl)-2-methylpyrrolo[3,2-e]1,2,4-triazolo[4,3-c]pyrimidin-3(2H)-thione (29). A mixture of hydrazine derivative $27(0.79 \mathrm{~g}, 3 \mathrm{mmol})$ and carbon disulfide $(4 \mathrm{~mL})$ in pyridine $(20 \mathrm{~mL})$ was heated on water bath for $4 \mathrm{~h}$. The solid product thus formed was filtered off, washed several times with water and recrystallized from dioxane to yield 29 as orange crystals in $0.87 \mathrm{~g}(69 \%)$ yield, m.p. $358-360{ }^{\circ} \mathrm{C}$. IR: $v=3380(\mathrm{NH}), 1630(\mathrm{C}=\mathrm{N}) \mathrm{cm}^{-1} .{ }^{1} \mathrm{H}-$ NMR (DMSO) $2.90\left(3 \mathrm{H}, \mathrm{s}, \mathrm{CH}_{3}\right), 7.4-8.8(10 \mathrm{H}, \mathrm{m}, \mathrm{ArH}$ and $\mathrm{CH}$ pyrrole), $9.1(1 \mathrm{H}, \mathrm{s}, \mathrm{NH}), 9.25(1 \mathrm{H}, \mathrm{br}, \mathrm{OH}$ quinoline) ppm.

7-(p-Tolyl)-9-(8-quinolinol-5-yl)-2-methylpyrrolo[3,2-e]1,2,4-triazolo[4,3-c]pyrimidine-3(2H)-one (30). To a cold solution of $27(0.79 \mathrm{~g}, 3 \mathrm{mmol})$ in pyridine $(10 \mathrm{~mL})$, ethyl chloroformate $(2 \mathrm{~mL})$ was added dropwise. The mixture was refluxed for $4 \mathrm{~h}$, then allowed to cool and poured into water. The solid thus obtained was filtered off and recrystallized from ethanol to afford 30 in $0.62 \mathrm{~g}(61 \%)$ yield, m.p. $>360$ ${ }^{\circ} \mathrm{C}$. IR: $v=3280(\mathrm{NH}), 1680(\mathrm{C}=\mathrm{O}) \mathrm{cm}^{-1} .{ }^{1} \mathrm{H}-\mathrm{NMR}$ (DMSO) $2.85\left(3 \mathrm{H}, \mathrm{s}, \mathrm{CH}_{3}\right), 7.4-8.8(10 \mathrm{H}, \mathrm{m}, \mathrm{ArH}$ and $\mathrm{CH}$ pyrrole $)$ ), $8.95(1 \mathrm{H}, \mathrm{s}, \mathrm{NH}), 9.15(1 \mathrm{H}, \mathrm{s}, \mathrm{OH}$ quinoline) $\mathrm{ppm}$.

Biological screening. The screened compounds were dissolved in DMSO to get a solution of $1 \%$ concentration. Filter paper discs (Whatman No. 1 filter paper, $5 \mathrm{~mm}$ diameter) were saturated with this solution. The discs placed on the surface of solidified Nutrient agar dishes seeded by the tested bacteria or Czapek's Dox agar dishes seeded by the tested fingi. The inhibition zones were measured at the end of an incubation period of $48 \mathrm{~h}\left(\right.$ at $37{ }^{\circ} \mathrm{C}$ for bacteria and at $28{ }^{\circ} \mathrm{C}$ for fungi). Tioconazole (Tyrosyd $\mathrm{d}^{\mathrm{R}}$ ) was used as a reference substance.

\section{References}

1. Lim, M. I.; Klein, R. S.; Fox, J. J. J. Org. Chem. 1979, 44, 3826.

2. Lim, M. I.; Klein, R. S.; Fox, J. J. Tetrahedron Lett. 1980, 21, 1013.

3. Lim, M. I.; Klein, R. S. Tetrahedron Lett. 1981, 22, 25.

4. Lim, M. I.; Ren, W. Y.; Otter, B. A.; Klein, R. S. J. Org. Chem. 1983, 48, 780 .

5. Mizuno, V.; Ikehara, M.; Suzaki, K.; Itoh, A. J. Org. Chem. 1963, $28,3329$.

6. Rao, K. V. J. Med. Chem. 1968, 11, 939.

7. Tolman, L.; Robins, R. K.; Townsend, L. B. J. Am. Chem. Soc. 1969, 91, 2102.

8. Roth, H. J.; Eger, K.; Issa, S.; Jacobi, H. J. Pharm. Sci. 1971, 60, 1236.

9. Singh, H. J. Sci. Ind. Res. 1978, 30, 176 
10. Khalil, Z. H.; Yanni, A. S.; Khalaf, A. A.; Abdel-Hafez, A. A.; Abdou, R. F. Bull. Chem. Soc. Jpn. 1988, 61, 1345.

11. Khalil, Z. H.; Abdel-Hafez, A. A.; Geies, A. A.; El-Dean, A. M. K. Bull. Chem. Soc. Jpn. 1991, 64, 668.

12. Khalil, Z. H.; Yanni, A. S.; Gaber, A. M.; Abdel-Mohsen, Sh. A. Phosphorus Sulfur and Silicon 2000, 162, 65.

13. Khalil, Z. H.; Yanni, A. S.; Gaber, A. M.; Abdel-Mohsen, Sh. A. Phosphorus Sulfur and Silicon 2000, 166, 57.

14. Abdel-Mohsen, Sh. A. Chin. Chem. Soc. 2003, 50, 1085.
15. Gewald, K.; Hentschel, M. J. Prakt. Chem. 1976, 318, 663.

16. Brown, R. E.; Wilson, J.; Shah, U.; Jones, H.; Love, B. J. Med. Chem. 1984, 27, 1639.

17. Ried, W.; Russ, Th. Collect. Czech. Chem. Commun. 1991, 56, 2288.

18. Dave, C. G.; Shah, R. D. Molecules 2002, 7, 554.

19. Bauer, A. W.; Kirby, W. W. M.; Sherris, J. C.; Turck, M. Am. J. Clin. Pathol. 1966, 45, 493.

20. Matsumura, K. J. Am. Chem. Soc. 1930, 52, 4433. 